\title{
Examining Two Middle School Mathematics Teachers' Knowledge for Teaching Manipulation of Algebraic Expressions during Lesson Planning and Instruction
}

\author{
Dilek Girit Yildiz ${ }^{a}$ and Didem Akyüz
}

aTrakya University, Faculty of Education, Tekirdağ/Turkey (ORCID: 0000-0003-3406-075X)
${ }^{\mathrm{b}}$ Middle East TechnicalUniversity, Faculty of Education, Ankara/Turkey (ORCID: 0000-0003-3892-8077)

Article History: Received: 24 November 2018; Accepted: 15 July 2019; Published online: 14 November 2019

Abstract: Teachers use their content and pedagogical content knowledge for teaching algebra. For this reason, the examination of how teachers use this knowledge may help shed light on how students learn algebra, especially in determining why they usually have difficulties. The aim of the current study is to reveal what teachers know, and propose what they actually need to know for teaching the simplification and equivalence of algebraic expressions. The multiple-case study design was used for this study to compare and contrast the two middle school teachers' lesson planning and instruction. The data corpus included lesson plans, actual instruction records, and post-observation interviews. Data analysis was conducted using the Mathematical Knowledge for Teaching (MKT) model. The findings indicated that both teachers had a lack of specialized content knowledge about mathematical representations such as algebra tiles. They did not use algebra tiles effectively and could not link algebraic and geometric representations that underlie the idea of multiplication. It was observed that both teachers generally used unknowns and variables interchangeably indicating the inadequacy of their common content knowledge. In the planning process, the two teachers were able to state the common misconceptions that the students generally had and the ways of addressing them. Through the cases of these two teachers, it was observed that teachers need to have a good conceptual mathematical understanding and also knowledge of students' thinking in order to design effective lessons. Based on the findings, the types of knowledge that the teachers need to have are outlined and the theoretical and practical implications of the study are discussed.

Keywords: Equivalence of algebraic expressions, mathematical knowledge for teaching, simplification of algebraic expressions, middle school mathematics teacher

DOI: 10.16949/turkbilmat.487243

\section{Introduction}

Teacher knowledge is an important component of teaching and plays a key role in students' learning. It has been shown that the teacher's content knowledge and pedagogical content knowledge of mathematics has a positive effect on students' mathematics achievement (Hill, Rowan, \& Ball, 2005). Especially, mathematics teachers' knowledge is essential to students' mathematics achievement (Blömeke \& Delaney, 2012). One of the mathematics learning areas where students generally have difficulty in middle and high school is algebra (Kieran, 2007). It is important to support students' ability to think algebraically in the elementary grades in order to help middle and high school students from not experiencing difficulties in algebra (Cai, $\mathrm{Ng}, \&$ Moyer, 2011). More specifically, the studies about learning algebra in the early grades show that students generally have

Correspondance: Dilek Girit Yildiz (iD) email: dilekgirit@gmail.com

Citation information: Girit-Yildiz, D. \& Akyüz, D. (2019). Examining two middle school mathematics teachers' knowledge for teaching manipulation of algebraic expressions during lesson planning and instruction. Turkish Journal of Computer and

Mathematics Education, 10(3), 588-616. 
difficulty in manipulating algebraic expressions (e.g., Banerjee \& Subramaniam, 2012; Booth, 1988; Gunnarsson, Sönnerhed, \& Hernell, 2016; Livneh \& Linchevski, 2007; MacGregor \& Stacey, 1997; Seng, 2010). Gallardo (2000) asserts that there is a didactic cut in the child's thought in the transition from arithmetic to algebra and that students have a resistance to operating with unknowns in the transition to algebraic thinking.

Kaput (2000) advocated teaching algebra in the early grades (6 to 12 years of age) and emphasized the importance of learning "the study of functions, relations, and joint variation" (p. 19). In connection with this description, two important concepts are variables and algebraic expressions (Subramaniam \& Banerjee, 2004). The development of these concepts is conceptually and procedurally important in forming an equation and solving it in later grades. The concept of variable is taught first in the context of generalization of patterns; then, algebraic expressions are taught conceptually and procedurally in the context of operations with algebraic expressions in relation to these generalizations (Capraro \& Joffrion, 2006). According to Kieran's (2007) model of algebraic activity, the generalization of patterns is a generalization activity. After this, the transformational activity comes which requires manipulating the symbolic form of an algebraic expression or an equation. The scope of this study hence involves the manipulation of algebraic expressions, which include adding, subtracting, and multiplying algebraic expressions. Simplification of algebraic expressions involves the collection of like terms, and equivalence of expressions involves the application of the distributive property in multiplying expressions. Teachers play an important role in teaching algebra since they are the ones who make decisions about algebra instruction (Malara \& Navarra, 2009). For this reason, the examination of the teachers' methods in teaching and the use of algebra knowledge in practice may shed light on understanding how students learn algebra in the transition from arithmetic to algebra and to determine why they usually have difficulty learning it. Thus, the aim of this paper is to determine teachers' algebra knowledge in teaching operations with algebraic expressions in middle grades. This paper seeks to address the following question: What is the nature of middle school mathematics teachers' mathematical knowledge for teaching the simplification and equivalence of algebraic expressions in lesson planning and instruction?

\subsection{Conceptual frame of teacher knowledge}

Teacher's knowledge as a term was first defined and used by Shulman (1986); since then, many researchers have identified the components of teacher knowledge and elaborated on this concept (Graeber \& Tirosh, 2008). In fact, it has been shown that content knowledge is more effective in teaching when combined with pedagogical knowledge (Ball, Thames, \& Phelps, 2008; Hill et al., 2005). Researchers in mathematics education also proposed models for teacher knowledge, especially in mathematics based on the frameworks of teacher knowledge (Cochran, DeRuiter, \& King 1993; Grossman, 1990; Shulman, 1986). There are different components which emphasized by the developers in these frameworks. In one of the frameworks, Fennema and Franke (1992) emphasized the use of real-life 
situations and manipulatives to promote students' understanding. Additionally, Rowland, Huckstep, and Thwaites (2005) proposed a contingency category which concerns the teachers' knowledge of handling unexpected situations which occur during teaching. There are also models specific to mathematics teachers' pedagogical content knowledge (PCK) (An, Kulm \& Wu, 2004; Chick, Baker, Pham, \& Cheng, 2006).

Broader and more detailed than these models, Ball et al. (2008) developed the mathematical knowledge for teaching (MKT) model. Ball et al. (2008) describe MKT as "the mathematical knowledge needed to carry out the work of teaching" (p. 395). Ball et al. (2008) analyzed teachers' practices and determined the mathematical demands of teaching in the development of their model. This model is a domain map which shows mathematical knowledge for teaching consisting of subject matter knowledge (SMK) and PCK (see Figure 1). SMK has common content knowledge (CCK) and specialized content knowledge (SCK) components. CCK is "mathematical knowledge that is used in teaching, but not directly taught to students" and it is used by people working with mathematics; SCK is specific to mathematics teachers (Hill, Sleep, Lewis, \& Ball, 2007, p. 132). According to Ball et al. (2008), PCK consists of knowledge of content and students (KCS), knowledge of content and teaching (KCT), and knowledge of content and curriculum (KCC). KCS is defined as "the knowledge that combines knowing about students and knowing about mathematics" (Ball et al., 2008, p. 401). Teachers must be aware of students' common conceptions and misconceptions, errors, and difficulties specific to a mathematical topic. KCS is a component of Shulman's PCK concept; it is apart from subject matter knowledge. The second subdomain of PCK is KCT. It is defined as "the knowledge that combines knowing about teaching and knowing about mathematics" (Ball et al., 2008, p. 401). Teachers need to know how to design instruction for teaching mathematics, lead a discussion, and make decisions about the instruction. The third subdomain of PCK is KCC. It is explained as the knowledge of the contents regarding the curriculum order, suggested activities, and important explanations for teaching.

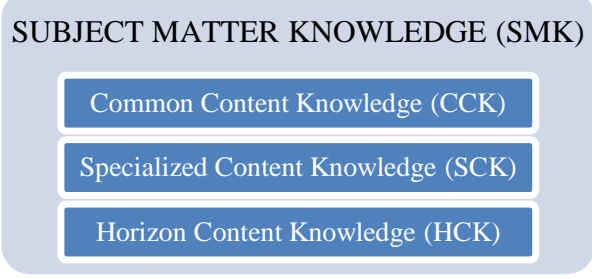

PEDAGOGICAL CONTENT KNOWLEDGE (PCK)

Knowledge of Content and Student (KCS)

Knowledge of Content and Teaching (KCT)

Knowledge of Content and Curriculum (KCC)

Figure 1. Mathematical Knowledge for Teaching Model (Ball et al., 2008)

Besides examining teacher knowledge in practice phase, the lesson imaging before the instruction is also important (Stephan, Pugalee, Cline, \& Cline, 2017). The researchers suggested that the teachers should explain the objective, design the task and how to carry it out, anticipate misconceptions, design the strategies and their order, prepare questions and determine how to be aware of students' understanding (Stephan et al., 2017). Sullivan et al. 
(2015) also added consolidating tasks which provide the connection with prior learning and supplementary tasks which provide easier or more difficult according to the need of the students. These researchers take teacher knowledge in planning into consideration and thus the current study also examined it by combining lesson planning and instruction.

Researchers have also attempted to explain teacher knowledge for particular mathematical topics, such as algebra (e.g., functions), probability and statistics (Graeber \& Tirosh, 2008). However, there is not much research in the literature about teachers' knowledge and practice of algebra (Doerr, 2004; El Mouhayar \& Jurdak, 2013; Wilkie, 2014). The studies in the past about teachers' SMK generally focused on functions, slopes, and equations (e.g. Even, 1990; Even, Tirosh \& Robinson, 1993; Stump, 1999). More recent studies focused on both the teachers' SMK and PCK for the middle grades and secondary grade level algebra topics, including inequalities, expressions, and equations (Artigue, Assude, Grugeon, \& Lenfant, 2001; Ferrini-Mundy, McCrory, \& Senk, 2006). Generally, teachers' knowledge of students' thinking as PCK was examined in the algebra word problem-solving context (e.g., Nathan \& Koedinger, 2000; Van Dooren, Verschaffel, \& Onghena, 2002). As is normally the case, the proposed models and frameworks are usually about algebra topics at the secondary level (Doerr, 2004). Although there have been studies about algebra knowledge, Wilkie (2014) has asserted that there are fewer studies about teachers' algebra knowledge as topic-specific in practice in the middle school grades. Thus, the main issue addressed in this paper is teacher knowledge in teaching manipulation of algebraic expressions by considering planning and teaching processes together. In particular, the current research focused on MKT of teachers in the context of manipulation of algebraic expressions. There are several reasons for using the MKT model in this study. Teacher knowledge is explained into sub-domains specific to mathematic teaching with this model (Hill, Ball, \& Schilling, 2008). Thus, it is considered to reveal existing teacher knowledge as specific to manipulation of algebraic expressions, which gives detailed descriptions of the knowledge domains. Another reason for using this model was that it was based on observations of teachers' instructions as qualitative aspect of the development of it. Since the main data of this study was observations of the instructions, the MKT model was found as appropriate. Considering the aims of the study under these contributions, since MKT model includes content knowledge and pedagogical content knowledge together, it was preferred to be used for this research.

\subsection{Teachers' knowledge of algebraic expressions}

There have been many discussions about teachers' knowledge and how it is related to teaching algebra. Some studies (e.g. Livy \& Downton, 2018; Stephens, 2008; Sullivan, 2018; Tchoshanov, Quinones, Shakirova, Ibragimova, \& Shakirova, 2017) suggest that preservice teachers need to have conceptual knowledge for teaching algebra. Teachers need to have knowledge of using multiple representations, justifying reasoning, using generalization and posing problems for teaching algebraic reasoning (Bair \& Rich, 2011). These requirements are about teachers' specialized content knowledge (SCK) of algebra 
and it is important to note that transferring SCK to practice is essential for effective teaching in early algebra topics such as the associative property (Ding \& Heffernan, 2018). However, Huang and Kulm (2012) showed that pre-service teachers did not manipulate algebraic expressions fluently in functions as CCK requirement. In more detail, pre-service teachers had difficulty with using representations and examples, and deep questions and so the content of teacher training programs can be discussed in order to support the teacher candidates' content knowledge of algebra with pedagogy (Ding \& Heffernan, 2018).

As well as pre-service teachers, in-service teachers can also have problems in teaching algebra. Tirosh, Even, and Robinson (1998) examined PCK in the context of algebraic expressions. They examined teachers' awareness of the students' tendency to conjoin or "finish" open expressions, as this tendency caused difficulty in learning algebraic expressions and operations associated with them. Students with this tendency can add $4 x+5$ as 9 or $9 x$, as an example. The researchers studied two novices and two expert seventh grade teachers, so categorized based on their years of teaching experience. Tirosh et al. (1998) found that the two novice teachers were not aware of this tendency, while the two experienced teachers expected that students had this tendency in dealing with algebraic expressions. The researchers observed that one novice teacher was unaware of the misconception that students could have; thus, he emphasized adding the numbers and letters separately, as a rule when teaching simplification of algebraic expressions, and the students gave incorrect answers. On the other hand, the other novice teacher used rules, adding "like terms" indicating the terms which had $x$ as like terms. She used fruit salad techniques while explaining operations in algebraic expressions by representing apples and pears for variables. However, the researchers observed that these strategies caused some confusion in student learning. One of the experienced teachers first explained what like terms and unlike terms were considering students' difficulties and continued the lesson using this concept. The other experienced teacher provided students with conceptualization by using challenging strategies, such as substitution, the order of operations, and going backward. Tirosh et al. (1998) suggested that teachers should know the students' difficulties and design their lessons using different approaches regarding the students' conceptions.

The knowledge of how students learn, and where students have difficulty are important elements of pedagogical content knowledge. In this context, Hallagan (2004) developed tasks which included modeling equivalent expressions, and the teacher implemented the tasks and constructed a library selecting students' different solutions. For example, students worked on showing and explaining that the $4 s+4$ expression was equal to $4(s+1)$, $s+s+s+s+4,2 s+2(s+2)$, and 4(s+2)-4 in different pictures. This task aimed to determine the perimeter of a square pool. As a result, the teacher recognized the value of using visual strategies based on area model to improve students' conceptual understanding rather than using only the distributive property as a procedure. Hallagan (2004) suggests developing a library which includes samples of students' works to enhance teachers' knowledge and improve algebra instruction. 
One of the components of teacher knowledge is knowing students' misconceptions as well as conceptions. Lucariello, Tine, and Ganley (2014) emphasized the importance of teacher's instruction that provides conceptual change about variable concept in algebraic expressions in order to overcome students' misconceptions about variable. They developed a diagnostic test to determine students' misconceptions to guide teachers on how they could handle the misconceptions before and after the instruction. They pointed out "variable is a label" and "a specific unknown" misconceptions that the students often have. When a variable is thought as a label, students could think the variable is standing for an object not the number of it. This misconception as reversal error is also related to multiplicative comparison in equality (Weinberg, Dresen, \& Slater, 2016). For example, the well known "students and professors" problem is "there are six times as many students as professors". The students could answer incorrectly as $6 S=P$ considering $S$ is a label rather than the number of students. The teachers should use multiplicative comparison problems to develop students' semiotic language and to support their understanding of the meaning of algebraic expressions (Weinberg et al., 2016).

Most of the studies in current research literature have examined algebraic expressions within other algebra topics such as equations, patterns or functions (e.g. El Mouhayar \& Jurdak, 2013; Even, 1990; Even et al., 1993; Ferrini-Mundy et al., 2006; Wilkie, 2014). Therefore, there is not much research about teachers' knowledge of manipulation of algebraic expressions as topic-specific knowledge and at middle school level (10-13 years). The current study aimed to make up for this lack in this area by examining algebraic expressions specifically. This study also goes a step further and examined teacher knowledge both in planning and teaching. This is important to reveal the teacher's role to support students' algebraic reasoning (Blanton \& Kaput, 2005; Carraher, Schliemann, Brizuela, \& Earnest, 2006). At that point, this study may contribute to the literature on algebra teaching and learning. Under this consideration, this paper seeks to address the following question: What is the nature of middle school mathematics teachers' mathematical knowledge for teaching the simplification and equivalence of algebraic expressions in lesson planning and instruction?

\section{Method}

\subsection{Research design}

In this study, the qualitative research design was used to uncover middle school mathematics teachers' mathematical knowledge for teaching in the context of algebraic expressions. In order to study teacher knowledge, taking the teaching process into consideration, qualitative research should be used (Kahan, Cooper, \& Bethea, 2003). Case study approach includes a case/cases that is/are explored by the researcher, detailed and indepth data collection from multiple sources (e.g. observations, interviews), and reporting the themes for the case (Creswell, 2007). Particularly, the multiple-case study design is preferred for this study to compare and contrast the exemplary outcomes of two teachers' instructions (Yin, 2003). The comparison of two cases could provide making an 
interpretation about the knowledge that the teachers should have by emphasizing the existing and lack of knowledge in two cases. The context is the algebraic expressions. The cases are two middle school mathematics teachers, and the unit of analysis is teachers' mathematical knowledge for teaching in this design.

\subsection{Participants}

The participants were two middle school mathematics teachers and they work in the same public school. They were teaching algebra topics to $7^{\text {th }}$ grade students at the same time during the data collection and thus these teachers were selected and convenient sampling method was used because of this accessibility. The teachers in this study had a master's degree in elementary mathematics education, and they have also been in a doctorate program in elementary mathematics education. One of the purposes of the study is to propose required knowledge types as a conceptual framework, thus the choice of these teachers can be considered appropriate. The names of the participants were changed for confidentiality, and code names were used as Ece and Eda to represent them.

\subsection{Data collection}

The data collection procedure had three phases in this study: pre-instruction, during instruction, and post-instruction. In the pre-instruction phase, the teachers prepared the lesson plans individually, and the researcher interviewed each teacher on their lesson plans. In the second phase, during instruction, the researcher observed the lessons in two different $7^{\text {th }}$ grade classes, took field notes, and video-recorded. After each class session, the researcher conducted post-observation interviews with the teachers (see Figure 2).
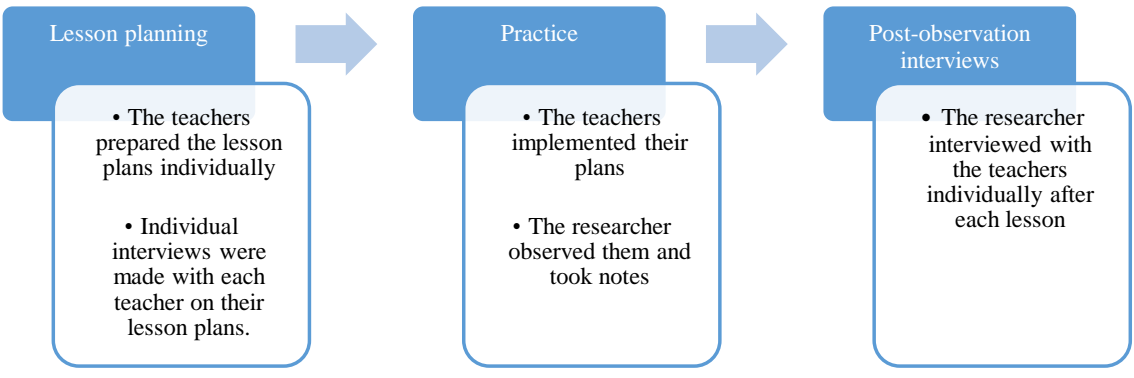

Figure 2. The process of data collection

The data collection process took about 24 class-hours ( 1 class-hour was 40 minutes), which included the total of two teachers' instructions. While the planning provided an understanding of the teachers' existing knowledge, the instruction provided an observation on how the teachers used their knowledge while teaching. The teachers prepared the lesson plans with the following objectives: "Add and subtract algebraic expressions, multiply a whole number and an algebraic expression, and multiply two algebraic expressions". The purpose of the post-observation interviews was to check whether the researcher understood 
the teacher's instruction properly by observing the lessons by comparing the teachers' responses. Thus, the data collection process of this study could give a holistic understanding of teaching with planning and instructions.

\subsection{Data analysis}

The analysis of the qualitative data begins by forming an initial and tentative coding and then continues with grouping them in themes with respect to similarities and ends with reporting the findings (Merriam, 2009). For this study, the cases as the two teachers' planning and instructions were analyzed and described independently first. The data from the cases were analyzed and coded as a statement, an explanation, a dialogue, or a question that was considered a meaningful unit. Then, the extracted codes were put into one of the themes and then sub-themes considering the descriptions and definitions of themes and subthemes in the MKT model.

In the analysis, SMK and PCK as knowledge domains were considered as themes and their components as knowledge sub-domains (CCK, SCK, KCS, KCT, and KCC) were considered as sub-themes for this study. This categorization provided an analysis of cases individually within itself. Yin (2003) suggested cross-case synthesis as an analytic technique for the analysis of two or more cases. The researcher can compare and contrast the cases based on the framework that is used for analysis. Thus, after forming these tentative codes, the codes which were categorized by comparing and contrasting and had a pattern in one case were also analyzed for the other case. From the analysis of two cases, the codes which occurred in the two cases within a pattern were determined for the current study. To ensure the reliability of the research, the data were coded separately by the researchers. Then the researchers came together to evaluate their coding and then reached a full agreement with discussing the coding. Besides, in this study, data were collected from several sources that were preparing lesson plans, interviews, and observations in order to provide trustworthiness.

\section{Findings}

In this section, the MKT of Teacher Ece and Teacher Eda are presented according to their lesson plans they prepared on the topic of algebraic expressions, the observations of the lessons they taught and interviews after each lesson.

\subsection{Teachers' lesson planning}

Ece designed the instruction of addition and subtraction with algebraic expressions by beginning with the questions in the textbook (Aydın \& Gündoğdu, 2016, p. 187) that had contexts requiring representation of given information algebraically and then carrying out the operations. One of the questions was like this:

Question: There are 2 eggs and 4 olives in one of the plates, and there are 1 egg and 6 olives in the other plate. In total;

How many eggs are there? 
How many olives are there?

Can you add olives and eggs?

Can you subtract eggs from olives?

Ece planned to ask the students to represent the number of eggs and olives algebraically and then how like terms were added when the eggs and olives were gathered. To illustrate, their addition was represented as $2 y+4 z$ ( $y$ represented egg, $z$ represented olive). However, the number of eggs and olives are known, thus it would be troublesome to represent the known situations with algebra concepts. After solving these questions, she planned to model addition and subtraction operations by using algebra tiles. The first example to model with algebra tiles was $(3 x-2)+(2 x+6)$ in her lesson plan. While modeling, she planned to represent the expressions separately first using the tiles as in the following figure:

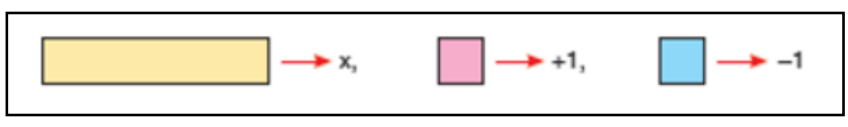

Figure 3. The representation of $x,+1$, and -1 with tiles in Ece's lesson plan

She explained the implementation of the modeling in planning. She indicated grouping the variables $(3 x$ and $2 x)$, and constant terms $(-2$ and +6$)$ separately and then adding these expressions in order to get the result as $5 x+4$ in her lesson plan.

On the other hand, Eda designed the instruction of addition and subtraction with algebraic expressions by beginning properties of operations. She planned to show these representations in the table that included the arithmetical operations and the corresponding operations with algebraic expressions. This table included the arithmetical operations in the first column, the algebraic representations of it in the second column, the terms in the third column, and the coefficients in the fourth column as exemplified for the first row as in the following table:

Table 1. Operations and their algebraic representations

$\begin{array}{llll}\mathrm{x}+2 x=3 \mathrm{x} & x, 2 x, 3 x & 1,2,3\end{array}$

Eda planned to begin with this matching activity and then, she planned to define like term concept as in the textbook.

For the instruction of multiplication with algebraic expressions, Ece planned to begin with Nermin's Money Activity in the textbook (Aydın \& Gündoğdu, 2016, p. 193). It was required to write algebraic expressions of verbal statements and the multiplication of a number and an algebraic expression. This activity was like in the following:

Nermin saves money from her allowance and has some in her moneybox. Nermin puts 5TL that her mother gave into her moneybox. Her father said that he would give her money twice as much as the saved money. Write the algebraic expression that Nermin would take from her father and explain how you would write it. 
Then, she planned to model multiplication operation by using algebra tiles. When she was asked how the tiles could provide the students to link to multiplication idea, she explained like this:

Ece: I will make these tiles by myself or I will want the students to prepare them. They can make by using colorful papers. These tiles modeled the multiplication of algebraic expressions. For example, $4 x$, suppose this represents " $x$ ". How many $x$ are there? Let's add. We put four of them side by side. Then, I connect like this; the shortcut is $4 . x$ of this addition operation. We can do like this.

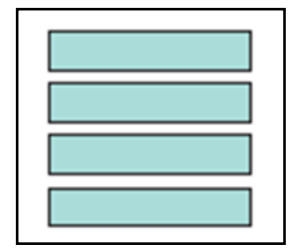

Figure 4. The representation of $4 x$ with algebra tiles

Ece explained that the algebra tiles would provide the demonstration of the repeated addition by putting 4 tiles side by side. She planned to link the representations for multiplication operation by using algebra tiles in this way. However, she did not indicate the concept of area calculation in this representation to link algebraic and geometric representations since her knowledge to choose, make and use the algebra tiles did not seem to support this. Focusing on repeated addition in this representation could not have provided this link to underlie the multiplication idea. She also expressed her concerns and anticipations about students' difficulties in applying the distributive property in multiplication and modeling with algebra tiles for multiplication:

Ece: The students can understand easily addition and subtraction by modeling with tiles. Since they see similar ones and add them to find their number. But, they have difficulty with the multiplication, especially while using distributive property such as 2. $(3 x+2)$. The students can confuse addition with multiplication. Perhaps, they can understand it by modeling with tiles. But they have difficulty using the tiles, also.

On the other hand, for the multiplication of algebraic expressions, Eda too planned to use algebra tiles. She planned to make links among algebraic and geometrical representations to give the idea of multiplication of algebraic expressions:

Eda: For multiplication, I will use algebra tiles, if there are, or I will prepare with papers, or I will draw on the board. The students can understand while using the area of a square because they know the area of a square well. They also can use 
the area of rectangle easily. The length of the sides is $x$ and $x$, the area of this square is $x^{2}$. When $x+3$ is asked, 3 units are added. They can connect the multiplication with the area concept with this activity.

After teaching multiplication with modeling, she planned to apply the distributive property for multiplying algebraic expressions procedurally. Therewith, when the researcher asked students might have what possible misconceptions on this topic, the teacher explained the misconceptions in addition and subtraction of algebraic expressions by giving examples as follows:

Eda: For example, in $3 x-x$, the students can forget 1 as the coefficient of $x$. They have difficulty; they cannot understand this 1 easily. ... Another example is $4 x+3 y$ -

$x$. They can add or subtract all the coefficients without considering whether the variables are the same or not.

She also pointed out the common misconceptions in multiplication:

Eda: When $x$ is multiplied by $x$, the students can get $2 x$. Higher achieving students do not make this error. Other students are generally confused about this. They know the result is $x^{2}$ from the area of a square. However, they make errors. Especially, if there is a coefficient of $x$, such as $2 x$. Multiplication of $2 x$ and $x$. They are more likely to make this error.

In sum, for teaching simplification of algebraic expressions, Ece's knowledge to choose which examples to start with was inappropriate since the questions were problematic for using variables. On the other hand, Eda's knowledge to choose which examples to start teaching addition and subtraction appeared efficient with connecting the properties of arithmetical operations that the students had learned before. However, her knowledge to choose which examples to take the students deeper into the content appeared limited because of focusing on the properties of operations, merely not just the like term. For teaching multiplication, Ece's knowledge of sequence activities was appropriate. The sequence for teaching multiplication of algebraic expressions included first connecting multiplication concept with real-life situations, then connecting repeated addition with multiplication, and than using models to show how the algebraic expressions were multiplied. However, she did not emphasize the area concept underlying modeling in using algebra tiles. On the other hand, Eda planned to use algebra tiles with modeling in multiplication (KCT).

Ece's knowledge to choose, make and use the algebra tiles as representation was appeared inadequately since focusing on repeated addition in using of algebra tiles could not have provided the link among algebraic and geometric representation that underlie the multiplication idea. On the other hand, Eda's knowledge to link algebraic and geometrical representations underlying the area concept and of how to choose, make, and use mathematical representations was appropriate. She explained the area concept that underly modeling multiplication of algebraic expressions with algebra tiles correctly (SCK). 


\subsection{Types of knowledge in instruction}

\subsubsection{Teachers' common content knowledge (CCK) of algebraic expressions}

This study revealed that the teachers' common content knowledge included mostly the knowledge of the definition of the terms, and solving or answering the questions related to algebraic expressions. Ece's knowledge of the constant term concept was incorrect as she did not accept it as a term in an algebraic expression. To illustrate, Ece did not take the constant term as a term and answered the questions incorrectly as explained in the following script:

Ece: $a^{2}-3 a-4+2 a+5 a^{2}$, how many terms are there? Is ' $a^{2}$ ' a term? Yes. Is ' $-3 a$ ' a term? Yes. Is '-4' a term?

Students: No.

Ece: What is it? It is a constant term, not the term. $2 a$ is a term, $5 a^{2}$ is a term. How many terms are there? 4 .

In this situation, Ece explained that -4 was not a term since it was a constant term. She knew that -4 was a constant term but she did not accept it as a term, so her knowledge to use the terms appeared incorrect. It showed her lack of content knowledge about term concept in the algebraic expression. In the post-interview, the dialogue about constant term was as follows:

Researcher: You did not accept the constant as a term.

Ece: Is it a term?

Researcher: The constant term is also a term.

Ece: So, we take it as a term?

Researcher: Yes, the term is described as the part that is divided by a plus or minus sign. You can examine like this. The constant is a special situation.

Ece: It is also a term. That's right.

On the other hand, Eda's knowledge to use the term, like term, the constant term, and coefficient concepts appeared to be well developed. She made explanations about algebraic expression and emphasized the like term concept and gave several examples in the instruction as below:

Eda: When an algebraic expression is told, the concept of the term comes to the mind. Let's look at $2 x-3 y+5$. The terms are considered with their signs. Here, the terms are $2 x,-3 y,+5$. Thus, if how many terms there are is asked, look at the parts which are divided by + and - signs. Here, there are 3 terms. The coefficient is the other concept. We call the coefficient as the number which is multiplied by the unknown in each term. The coefficient of $x$ is $2(2 x)$, and the coefficient of $y$ is -3 . Be careful! We take it as minus with its sign. We call the constant term as the term which is not multiplied by any unknowns. 
Another situation that could be problematic for the two teachers was that they used the unknown and variable concept as if they had the same meaning. To illustrate, Ece used two examples: $8 t+3$ and $-9 x-7$. She explained that 8 and -9 were the coefficients; $t$ and $x$ were the unknowns; 3 and 7 were the constant terms; and $8 t$ and $-9 x$ were the terms. She used the unknown and variable concept together as they had the same meaning since she wrote "variable/unknown". Eda also used these concepts similar to Ece. The teachers did not differentiate between them because their knowledge of these terms was inadequate.

In general, Eda solved the questions and problems correctly with adequate explanations; however, Ece could not solve or answer the questions related to algebraic expressions correctly since she ignored what was given or asked several times during the instruction. Ece answered what she found instead of what was asked in the question. To illustrate, she found $2 n+10$ correctly by multiplying 5 and $(n+2)$ but she incorrectly expressed what it referred to. She expressed $2 n+10$ as the total money in the money box, but she should have added $2 n+10$ and $n+5$, and got $3 n+15$ for total. Another example was that she did not simplify $3(X+Y)+3(Y+7 Z)$ expression and thus she indicated that it did not match with any expressions in options equally. In other words, she missed some points, thus she did not answer the other questions in planning correctly and completely.

\subsection{Teachers' specialized content knowledge (SCK) of algebraic expressions}

This study revealed that the two middle school mathematics teachers' specialized content knowledge included mostly the knowledge to use representation, to provide mathematical explanations, and to use the mathematical language. Although Ece did not correct the students' incorrect use of the equal sign or determining the term without the sign, she used the notations appropriately by herself in the instruction of operations with algebraic expressions. For example, in simplifying $(2 x+1) 2+5 x$, a student first multiplied $2 x+1$ by 2 and then wrote $5 x$ next to the result of the multiplication and he used the equal sign inappropriately as shown in Figure 5.

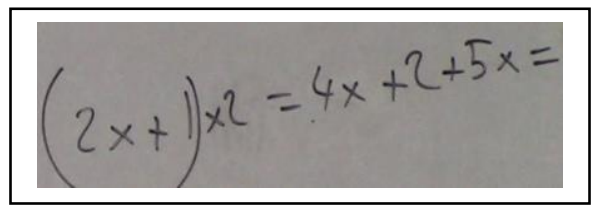

Figure 5. The use of equal sign by a student

In this situation, Ece did not correct this representation, and regarded the result as correct and explained this student's solution to the class, so her knowledge of how mathematical language was used appeared inappropriate. In contrast to this, Eda corrected the errors in the use of the equal sign appropriately and explained and corrected the students' incorrect writings. When the students collected the like terms separately in 
another place and they did not write them as a result as in Figure 6, Eda corrected and wrote them as the result in the right side of the equal sign.

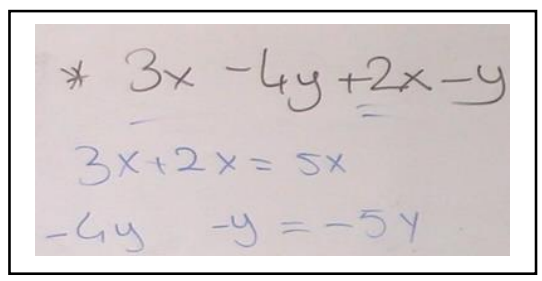

Figure 6. The writing for the simplification of $3 x-4 y+2 x-y$

Eda also represented the kind of variable with apple and pear analogy, and the procedures with net worth concept by using asset-debt concepts properly in order to teach addition and subtraction. To illustrate, she made explanations for the simplification of $3 x+4 a-5 x-2 a+7$ as in the following script:

Eda: Let's examine this example: $3 x+4 a-5 x-2 a+7$. Which of them are like?

Student: $3 x$ and $5 x \ldots$ one more, $4 a$ and $2 a$.

Eda: What is 7 ?

Student: The constant term.

Eda: Then, you have $3(3 x)$ apples and you are told to give 5 apples to someone.

Can you give?

Students: No.

Eda: What then? You owe 2 apples. That's $-2 x$. Then, I have 4 pears $(4 a)$, and you are told to give 2 pears to someone.

Student: $+2 a$ is left.

Eda: $-2 x+2 a$. There is 7 but there is nothing to add with it. The result is $-2 x+2 a+7$.

The students could find the like terms as $3 x$ and $5 x$, and $4 a$ and $2 a$. Eda asked the students to add them by representing apples for $x$ and pears for $a$, and net worth for operations. In this example, her knowledge of mathematical language use by expressing the procedures with net worth concept through using assets and debts concepts as analogy appeared appropriate. Actually, she had stated to use rectangular and unit square papers to represent the variables in the lesson planning, but she did not use them in the instruction. Instead of this, she used apple-pear analogy to represent the kind of variables.

In teaching multiplication of algebraic expressions, the teachers' connection with the prior topic in order to explain the distributive property of multiplication appeared appropriate in different ways. Ece connected multiplication with repeated addition to explaining this property. Ece wanted the students to model $4 x$ as "Is it the long way, $x+x+x+x$, to add 4 of $x$ ? We have multiplied 4 by $x$, and that's $4 . x=4 x$ " (see Figure 7). 


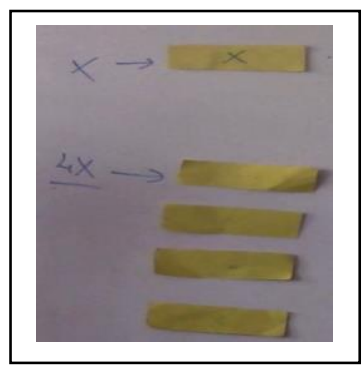

Figure 7. The representation of $4 x$ with algebra tiles

In this situation, Ece represented $4 x$ using the 4 algebra tiles of $x$ as seen in the figure. She did not make explanations about the meaning of $4 x$, which was the area of the rectangle whose sides were 4 and $x$, and so she did not indicate the area concept. On the other hand, Eda connected the application of this property with integers appropriately. However, the teachers' conceptions about algebra tiles appeared different and inadequate. While Ece used the tiles focusing on repeated addition by counting the number of tiles, Eda did not use them in her instruction though she emphasized the importance of using connecting the area concept in planning. Neither of the teachers used algebra tiles effectively and linked algebraic and geometric representation to underlie the multiplication idea. Their knowledge to evaluate the instructional advantages and disadvantages of algebra tiles as representations were inadequate in the post interviews.

In the multiplication of two algebraic expressions, Ece did not provide adequate mathematical expressions. To illustrate, some students had difficulty in the conceptualization of $n^{2}$ in the multiplication of $2 n$ by $3 n$. Ece asked a student to explain why the result was $n^{2}$ and approved his explanation. The students said that "Because there are two ' $n$ 's." In this situation, the student's answer was acceptable since he could think that there were two n's multiplied. However, Ece's response to the student was not adequate as a mathematical explanation since the existence of two items does not always yield $n^{2}$. To illustrate, $n+n$ expression had two items of $n$ and yielded $2 n$. Thus, her knowledge of how mathematical language was used appeared inappropriate. Instead of this, the teacher might have stated that there were 2 multiplied items of $n$.

\subsection{Teachers' knowledge of content and students (KCS) in algebraic expressions}

This study revealed that the two middle school mathematics teachers' knowledge of content and students included mostly the knowledge to anticipate where and how the students have difficulty and possible misunderstandings. Generally, Ece's knowledge to anticipate the misunderstandings that might arise while studying like terms were inadequate since she emphasized only the kind of variable without considering its power. She explained the like term concept stating that it had the same variables with same or different coefficients; however, this definition was inadequate as $x$ and $x^{2}$ were the expressions that 
had the same variable but they were unlike terms and the definition could cause misconceptions. Ece did not show the signs of the constant term while determining it, either. On the other hand, Eda explained the like term concept, the procedures of the addition operation, and the sign before the parenthesis adequately with her knowledge of understanding the difficulties of students and considering the needs of the students. For example, she indicated the requirement of the same variable and power for like term as in the script:

Eda: ...The terms whose variables and powers are same are like terms. For example, $3 x$ and $-5 x$. Are they like, $a^{2}$ and $4 a^{2}$ ?

Students: Yes.

Eda: $3 x^{2}$ and $3 y^{2}$ ?

Students: They are not.

Eda: Yes, look at the variables. $4 x^{2}$ and $4 x$ ? Are they like terms?

Student: They are not because one of them does not have a power.

In the planning process, the teachers had stated common misconceptions that the students could have based on their previous experiences such as the students' thinking of $4 . x$ as a two-digit number, or $x . x$ as $2 x$, or ignoring 1 as the coefficient of $\mathrm{x}$ in $3 x-x$, or adding unlike terms. The teachers also noticed these misconceptions in the instructions.

In Ece's class, the students added unlike terms. To illustrate, in finding $a+b$ when $a=(2 x-1), b=3(x+3)$, a student did operations as in the following script:

Student: Since there is not a distribution in $a$, I am writing $2 x-1=1$ (The teacher corrected it, then the student is distributing 3 to $(x+3)$ for $b$ as in Figure 8)

Ece: Have you found $12 x$ from adding $3 x$ and 9? Are they like terms? (The student is writing $3 x+9$ ). Add $2 x-1$ and $3 x+9$.

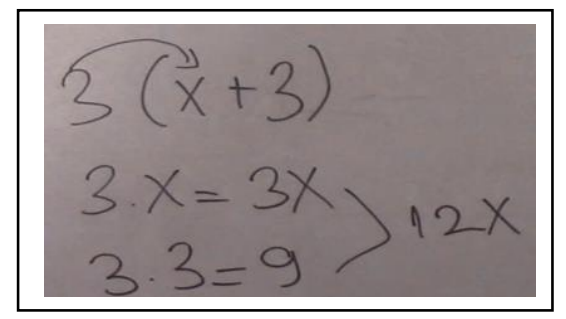

Figure 8. The misconception related to adding unlike terms

In this situation, the student explained $2 x-1=1$ incorrectly. However, $2 x$ and -1 were not like terms and thus they could not be added or subtracted. Ece did not make any explanations about the fact that these terms were not the like terms, and she only erased 1. Then, the student used the distributive property for $b$, and he found $3 x$ and 9 , added them and found $12 x$, which was incorrect. Ece asked the student to add $2 x-1$ and $3 x+9$. Although 
some students, as it is seen, could not conceptualize the like term concepts for addition and subtraction, Ece did not provide any explanations again. Her knowledge of how to address the student's errors and correct them appeared inadequate. Since she realized the student's errors during instruction, she only corrected them herself, but she did not ensure if the errors were corrected and if the students learned the concepts conceptually. Another example was related to ignoring coefficient ' 1 ' of the variable in Eda's class as in the following script:

Eda: What are the terms in $a-2 b+7$ ?

Student: 2 and 7.

Eda: The terms? Each of them is a term here: $a,-2 b$, and $7 \ldots$ What are the coefficients?

Student: -2 and 7.

Eda: Are you sure?

Student: There is 1 in $a$.

Eda: How many ' $a$ 's are there in this expression? 1 . The other coefficients: 1 and 2. It does not matter whether it is $a$ or $x$. If there is one variable, the coefficient of it is 1 .

In this situation, Eda corrected the students' answers while they were determining the terms. The students could not consider that the coefficient of the variables was 1 if there is no number in front of it. Eda explained that there was one ' $a$ ' in the expression and so the coefficient of it was 1 . Her knowledge to address the students' errors and to correct them appeared effective in her explanation while doing this exercise.

Last, in the instruction of multiplication of algebraic expressions, Eda especially emphasized the difference between area and perimeter concepts. Her knowledge to anticipate the misunderstandings that might arise while studying these concepts in solving problems related to geometry was appeared.

\subsection{Teachers' knowledge of content and teaching (KCT) of algebraic expressions}

This study revealed that the two middle school mathematics teachers' knowledge of content and teaching included mostly choosing examples to start and take the students deeper into the content. Generally, the teachers' knowledge to choose examples and activities to start and then to take the students deeper into the topic was appropriate. In the simplification of algebraic expressions, Ece started with connecting the like term concept with real-life situations. She used problems related to real-life situations for teaching; however, her knowledge to choose which examples to use to take the students deeper into the content was inappropriate as she represented the number of known items with algebraic representations. To illustrate, she implemented the activity to make the students feel the need of like terms for addition. This activity had two plates, one of which had 2 eggs and 4 olives, and the other had 1 egg and 6 olives. The teacher drew two plates on the board and asked how eggs and olives could be added: 
Ece: How can we express the addition of eggs and olives?

Student: $2 y+4 z$.

Ece: That's it! You have added eggs and olives separately. It is the same for the second plate. $1 y+6 z$. Can we not write 1 as the coefficient of $y$ ?

Students: Yes.

Ece: $y+6 z$.

Student: Why do we express them as $y$ and $z$ ?

Ece: We used the letters to represent egg and olive.

This question enabled the students to think the similar ones could be added. The teacher used this activity to connect it with the concept of like terms as mathematical ideas. However, the student answered as $2 y+4 z$, and Ece accepted this answer and the teacher also expressed the second plate as $1 y+6 z$ algebraically. The number of eggs and olives were known in these plates and thus expressing them algebraically was troublesome. That was, one student, did not understand why eggs and olives were represented with $y$ and $z$ letters. Different from Ece, Eda started by connecting the properties of arithmetical operations that the students had learned before. Then, she emphasized the like term concept by using different colored unit cubes to take the students deep into addition and subtraction.

In equivalence of algebraic expressions, Ece chose repeated addition to represent multiplication and used algebra tiles. She asked what $(4 m-3)+(4 m-3)$ was and a student added the like terms and got the correct result as $8 m-6$. Therewith, Ece guided the students to find the common number in the expression and show as $2(4 m-3)$. She also used the tiles by indicating repeated addition as explained above. On the other hand, Eda focused on the application of distributive property by connecting it with integers. She selected these two similar structures, 3(4-1) and 3(x-1), from arithmetic and algebra to explain the distributive property for multiplication of algebraic expressions connecting with arithmetic. The dialogue between Eda and the student is as follows:

Eda: For example, we did 3(4-1). What do we do if there is a number before the parenthesis? Normally, you do the operations in the parenthesis. Also, we said another method.

Student: Multiply 3 by 4 , and then 3 by -1 .

Eda: Okay ... If it is $3(x-1)$, compare the two of them. We write $x$ in the place of 4 .

What can we do? We can distribute 3 , multiply 3 by $x, 3 x ; 3$ by $-1,-3$. That's $3 x-3$.

Her knowledge of connecting algebraic and arithmetical structure was appropriate. She explained the distribution procedurally and then used this rule for the next multiplications.

In sum, the teachers have partially adequate knowledge for teaching manipulation of algebraic expressions. The findings also showed that the knowledge components (CCK, SCK, KCS, and KCT) are interrelated with each other. Teachers' appropriate subject matter knowledge influenced positively pedagogical content knowledge and how they teach algebraic expressions. 


\section{Conclusion and Discussion}

The purpose of this study is to reveal what types of knowledge mathematics teachers have in lesson planning and how they use them in their practices and to propose what mathematical knowledge they need for teaching operations with algebraic expressions. In the following section, these issues are discussed, and the implications and suggestions to develop teaching with respect to teacher knowledge in practice are presented.

\subsection{What do teachers know and what other knowledge types do they need to have to teach algebraic expressions?}

Regarding CCK, the teachers used the unknown and variable concepts as if they had the same meaning; they did not differentiate between them because their knowledge of these terms was inadequate. Similarly, Dogbey (2016) noted the teachers' limited understanding of the use of variables in different contexts. There are different uses of variables in generalized arithmetic and in solving problems. Variables are generalized numbers in operations, such as addition and multiplication and the relationship of patterns, while they are unknowns or constants in solving equations in the problem contexts (Usiskin, 1988).

Regarding SCK, Eda's apple-pear analogy was used by one of the novice teachers; this method was called the fruit salad method in Tirosh et al.'s (1998) study, and it provided an explanation of the addition and subtraction of different variables. The teacher in this study used this analogy when the students had difficulty understanding simplification; consequently, the students answered the questions correctly. However, Tirosh et al. (1998) asserted that this method did not provide a relational understanding of operations with algebraic expressions. However, Ojose (2015) suggested the use of this type of real-life example, such as apples and oranges, as a model to teach adding unlike terms. Filloy and Sutherland (1996) found that the use of concrete models, such as tiles or the apple-pear analogy, helps students' transition to the abstract level. In the multiplication of algebraic expressions, Hallagan (2004) developed tasks to explore the equivalence of expressions using area modeling such as $4(s+1)$ and $4 s+4$. These types of activities were implemented, and the development of students' understanding of equivalent expressions was observed. However, Ece used algebra tiles for explaining repeated addition in the multiplication of algebraic expressions. Caglayan (2013) stated that multiplication can be modeled by repeated addition, but the reasoning of multiplication requires explaining area modeling. On the other hand, Eda appropriately connected with the application of this property in integers. This method is also suggested by Ojose (2015) as exemplifying with integers first and then connecting algebraic expression to help the students' learning. While Ece used the tiles focusing on repeated addition with counting the number of tiles, Eda did not use them in her instruction, though she emphasized the importance of using algebra tiles for connecting the area concept in lesson planning. Thus, the two teachers did not use algebra tiles effectively and did not link algebraic and geometric representation to underlie the multiplication idea. They used them to provide visuals and concreteness. However, combining geometrical reasoning with other learning areas is one of the targets of 
mathematics teaching (National Council of Teachers of Mathematics [NCTM], 2000). The exploration of the multiplication of algebraic expressions by connecting the sum areas of tiles provides conceptual understanding (Caglayan, 2013). Bair and Rich (2011) emphasized the importance of using multiple representations to develop teachers' SCK.

Regarding KCS, Ece's explanation of the like terms concept could cause misconceptions. As Tirosh et al. (1998) indicated that the novice teacher who explained like term as having $x$ was not aware of the students' misconceptions about adding unlike terms, and the students had difficulty in simplification of algebraic expressions. In contrast, Eda emphasized the parentheses in operations considering the difficulties and the needs of the students. The studies suggest emphasizing the brackets while teaching operations to elementary level students (Hoch \& Dreyfus, 2004; Marchini \& Papadopoulos, 2011). However, it is important to note the understanding of the structural sense of algebraic expressions by focusing on quantitative relationships as operations and representations symbolically by using the same and different letters in order to prevent students' errors and improve conceptual understanding (Molina, Rodríguez-Domingo, Cañadas, \& Castro, 2017). In the planning process, the teachers also stated common misconceptions which the students could have based on their previous experiences, such as the students' thinking of $4 x$ as a two-digit number, and the teachers encountered these misconceptions which Seng (2010) identified. In the instruction of multiplication of algebraic expressions, Eda especially emphasized the difference between area and perimeter concepts. As she stated, the students can confuse the perimeter and area concepts, and the reason might be their formulas or representing the same region (Ashlock, 2006).

Regarding KCT, the real-life examples that Ece chose to start simplification of algebraic expressions were not appropriate because they had known values and could not appropriate for representing these values algebraically. For teaching multiplication, Ece's knowledge of sequence activities was appropriate. She used a real-life example to start and then used repeated addition to explain multiplication. However, she could not use algebra tiles effectively. On the other hand, Eda's knowledge to choose which examples to start teaching addition and subtraction appeared efficiently by connecting the properties of arithmetical operations that the students had learned before. Eda started by connecting the properties of arithmetical operations, which was one of the commonly suggested approaches for connecting arithmetic with algebra (Banerjee \& Subramaniam, 2012; Livneh \& Linchevski, 2007; Subramaniam \& Banerjee, 2004). Molina et al. (2017) also pointed out that the lack of understanding of the relationships in arithmetic expressions can cause errors in structuring algebraic expressions. Next, Eda emphasized the like term concept using different colored unit cubes to take the students deeper into addition and subtraction, as Filloy and Sutherland (1996) suggested. However, Eda did not use algebra tiles for teaching multiplication as she indicated in lesson planning.

In addition to the teachers' existing knowledge as explained above, this study also proposed, based on the literature, what types of knowledge teachers need to have to teach operations with algebraic expressions. 
In addition to KCS, Tirosh et al. (1998) pointed out that the teachers should design lessons considering the students' difficulties. Particularly when teachers instruct multiplication, it was found that the students generally do not have an adequate understanding of the structure of expressions, and they have difficulty understanding the concept of the distributive property (Kieran, 1989). Therefore, the teachers can emphasize the structure of algebraic expressions in order to support students' understanding. Teachers should also be aware of possible misconceptions that the students could have when they design lessons. In addition to teachers' identified misconceptions, others include incorrect order of operations, incorrect addition of integers, incorrect multiplication of a negative integer before the bracket, ignoring the multiplication of the second term in the brackets in using the distributive property, and incorrectly writing the result of addition of exponential forms (e.g., $7 a^{2}$ as $14 a$ ) (Seng, 2010). Also, intuition about new notations, misapplication of rules, operating with negative integers, and inadequate conceptions about the structure of algebraic expressions can cause the students to encounter difficulties (MacGregor \& Stacey, 1997; Seng, 2010). Moreover, Novotná, and Hoch (2008) showed that the lack of structural sense in high school students prevented them from understanding abstract algebra at the university. Thus, teachers should have knowledge of these common misconceptions and the possible reasons for them. For both simplification and multiplication, students' reasoning in algebra could also be an important component of KCS. Lepak, Wernet, and Ayieko (2018) proposed the concept of students' reasoning in algebra and defined it as making sense of context in problems, identifying quantities and relationship between them, representing them algebraically, executing calculations, and justifying solutions. Teachers should take into these competences consideration to support students' algebraic reasoning and also develop their KCS of algebra.

In addition to $\mathrm{KCT}$, teachers can use substitution, the order of operations, and going backward strategies to teach simplification of algebraic expressions (Hallagan, 2004; Tirosh et al., 1998). In order to build the students' thinking ability, teachers can present the procedures of operations with algebraic expressions by connecting the arithmetic procedures based on the similarity of the structure of expressions. This improves the students' understanding of rules and procedures in operations, simplifications of algebraic expressions, and the equivalence of the expressions (Banerjee \& Subramaniam, 2012). Besides, teachers should use strategies and tasks that would attract students' interest in combining pedagogical elements of social constructivism in teaching algebra (Prendergast \& O’Donoghue, 2014).

In addition to KCC, Wilkie (2014) proposed that teachers could evaluate the content descriptions with scaling. Thus, the knowledge to evaluate objectives, content descriptions, and sample activities related to the algebra topics in the curriculum could be considered as KCC which the teachers need to have.

In sum, the MKT which teachers should have for teaching operations with algebraic expressions can be proposed as in Table 2: 
Table 2. The proposed knowledge types for teaching manipulation of algebraic expressions

Knowledge Description (specific for teaching algebraic expressions)

types

The knowledge to use the concepts of the term, like term, constant term, and coefficient correctly

CCK The knowledge to use the concept of variable and unknown correctly

The knowledge to solve math problems related to operations with algebraic expressions correctly

The knowledge to develop or choose the usable definition of the term, like term, coefficient, constant term, and variable concepts

The knowledge to connect multiplication of algebraic expression with repeated addition as prior topic / The knowledge to connect the distributive property in multiplication with the application of it in integers

SCK The knowledge to link algebraic representation to the concept of area to geometric representation with algebra tiles

The knowledge of how analogies as mathematical language are used for explaining the kind of variables and the operations

The knowledge of how notations (equal sign and minus sign) are used

The knowledge of how mathematical language is used for explaining the multiplication of a variable by itself

The knowledge to anticipate the students' difficulty in the application of distributive property in multiplication

The knowledge to anticipate the misunderstandings that might arise while studying like term concept

The knowledge of students' common misconceptions about the multiplication of a

KCS number and a variable or a variable by itself

The knowledge to understand the difficulties of students in operating with the parenthesis algebraic expressions

The knowledge of common students' misconception about the perimeter and area concepts of rectangle

The knowledge to choose which examples to start teaching addition and subtraction appeared efficiently by connecting the properties of arithmetical operations

KCT The knowledge to decide when to ask how to collect/simplify terms in classroom discussion

The knowledge of how to address the students' errors in determining like terms and correct them

The knowledge to evaluate the advantages or disadvantages of using algebra tiles in teaching multiplication

KCT The knowledge of how to address the possible errors of students in calculating the area and perimeter of squares or rectangles using algebraic expressions and correct them

KCC The knowledge to know and evaluate the content and objectives in the curriculum related to operations with algebraic expressions 


\subsection{Implications and suggestions}

One of the most important implications of this study is the proposed knowledge types specific to operations with algebraic expressions (see Table 2). The proposed knowledge types can be used to develop algebra knowledge models, and, thus, this study might contribute to teacher knowledge of algebra. Teacher knowledge can also be examined in other algebra topics, such as equations, slope, and linear equations, in the middle grades in order to provide a general overview of the algebra knowledge of teachers. The proposed knowledge types can also be used to train pre-service and in-service teachers. The courses in teacher training programs can include the use of specific representations, models, mathematical language, instructional methods, and teaching techniques to develop teachers' knowledge. The school practicum courses can also be designed to develop pre-service teachers' teaching practice, and, therefore, developing teaching practices can enhance preservice teachers' specialized content knowledge (Aslan-Tutak \& Ertaş, 2013).

Other implications include the necessity of developing teachers' knowledge of using particular representations or materials and the teachers' knowledge of students' thinking, as essential elements for the effective teaching of mathematics. To support in-service teachers, meetings can be conducted where the teachers come together and share examples and experiences from their classes, ask for suggestions about what they can do, and note where they have difficulty in their teaching. Mathematics education researchers can also inform the teachers about the results of their studies and suggest activities or examples and methods from the literature for these training sessions.

There might also be different knowledge descriptions within different contexts, such as numbers or geometry. However, Horizon Content Knowledge (HCK) (Ball et al., 2008) for teaching algebra topics was not observed in the current study. Therefore, future research should also concentrate on the investigation of teachers' knowledge at the mathematical horizon of algebra to help the development of students' understanding of algebra in middle school grades.

This study presents an opportunity to discuss teacher knowledge as topic specifically within different components. As further research, on a qualitative level, the number of teachers can be increased, and, on a quantitative level, research can be carried out to make a generalization for teachers' knowledge of algebra by developing CK and PCK tests.

\section{References}

An, S., Kulm, G., \& Wu, Z. (2004). The pedagogical content knowledge of middle school teachers in China and the U.S. Journal of Mathematics Teacher Education, 7, 145-172.

Artigue, M., Assude, T., Grugeon, B., \& Lenfant, A. (2001). Teaching and learning algebra: Approaching complexity through complementary perspectives. In H. Chick, H. K. Stacey, J. Vincent, \& J. Vincent (Eds.), Proceedings of the 12th ICMI Study 
Conference: The Future of the Teaching and Learning of Algebra (pp. 21-32). Australia: University of Melbourne.

Ashlock, R. B. (2006). Error patterns in computation: Using error patterns to improve instruction. Colombus: OH: Merrill Prentice Hall.

Aslan-Tutak, F., \& Ertaş, F. G. (2013, February). Practices to enhance preservice secondary teachers' specialized content knowledge. Paper presented at the Eighth Congress of European Research in Mathematics Education (CERME 8), Antalya, Turkey.

Aydın, E., \& Gündoğdu, L. (2016). Middle school $6^{\text {th }}$ grade mathematics textbook. Ankara, Turkey: Sevgi Publications.

Ball, D. L., Thames, M. H., \& Phelps, G. (2008). Content knowledge for teaching: What makes it special? Journal of Teacher Education, 59(5), 389-407.

Bair, S. L., \& Rich, B. S. (2011). Characterizing the development of specialized mathematical content knowledge for teaching in algebraic reasoning and number theory. Mathematical Thinking and Learning, 13(4), 292-321.

Banerjee, R., \& Subramaniam, K. (2012). Evolution of a teaching approach for beginning algebra. Educational Studies in Mathematics, 80(3), 351-367.

Blanton, M. L., \& Kaput, J. J. (2005). Characterizing a classroom practice that promotes algebraic reasoning. Journal for Research in Mathematics Education, 36(5), 412-446.

Blömeke, S., \& Delaney, S. (2012). Assessment of teacher knowledge across countries: A review of the state of research. ZDM Mathematics Education, 44, 223-247.

Booth, L. R. (1988). Children's difficulties in beginning algebra. In A. F. Coxford \& A. P. Shulte (Eds.), The ideas of algebra, K-12 (pp. 299-306). Reston: National Council of Teachers of Mathematics.

Caglayan, G. (2013). Prospective mathematics teachers' sense-making of polynomial multiplication and factorization modeled with algebra tiles. Journal of Mathematics Teacher Education, 16(5), 349-378.

Cai, J., Ng, S. F., \& Moyer, J. C. (2011). Developing students' algebraic thinking in earlier grades: Lessons from China and Singapore. In J. Cai, \& E., Knuth (Eds.), Early algebraization: A global dialogue from multiple perspectives. (pp. 25-41). Verlag Berlin Heidelberg: Springer.

Capraro, M. M., \& Joffrion, H. (2006). Algebraic equations: Can middle-school students meaningfully translate from words to mathematical symbols? Reading Psychology, 27(2-3), 147-164.

Carraher, D. W., Schliemann, A. D., Brizuela, B. M., \& Earnest, D. (2006). Arithmetic and algebra in early mathematics education. Journal for Research in Mathematics Education, 37(2), 87-115.

Chick, H. L., Baker, M., Pham, T., \& Cheng, H. (2006). Aspects of teachers' pedagogical content knowledge for decimals. In J. Novotná, H. Moraová, M. Krátká, \& N. Stehlíková (Eds.), Proceedings 30 $0^{\text {th }}$ Conference of the International Group for the Psychology of Mathematics Education (Vol. 2, pp. 297-304). Prague: PME. 
Cochran, K. F., DeRuiter, J. A., \& King, R. A. (1993). Pedagogical content knowing: An integrative model for teacher preparation. Journal of Teacher Education, 44(4), 263272.

Creswell, J. W. (2007). Qualitative inquiry and research design: Choosing among five traditions $\left(2^{\text {nd }}\right.$ ed.). Thousand Oaks, CA: Sage Publications.

Ding, M., \& Heffernan, K. (2018). Transferring specialized content knowledge to elementary classrooms: Preservice teachers' learning to teach the associative property. International Journal of Mathematical Education in Science and Technology, 49(6), 899-921.

Doerr, H. M. (2004). Teachers' knowledge and the teaching of algebra. In K. Stacey, \& H. Chick (Eds.), The Future of the Teaching and Learning of Algebra: The 12th ICMI Study (pp. 267-290). Dordrecht, The Netherlands: Kluwer.

Dogbey, J. (2016). Using variables in school mathematics: Do school mathematics curricula provide support for teachers? International Journal of Science and Mathematics Education, 14(6), 1175-1196.

El Mouhayar, R. R., \& Jurdak, M. E. (2013). Teachers' ability to identify and explain students' actions in near and far figural pattern generalization tasks. Educational Studies in Mathematics, 82(3), 379-396.

Even, R. (1990). Subject matter knowledge for teaching and the case of functions. Educational Studies in Mathematics, 21(6), 521-544.

Even, R., Tirosh, D., \& Robinson, N. (1993). Connectedness in teaching equivalent algebraic expressions: Novice versus expert teachers. Mathematics Education Research Journal, 5(1), 50-59.

Fennema, E., \& Franke, M. L. (1992). Teachers' knowledge and its impact. In D. A. Grouws (Ed.), Handbook of research on mathematics teaching and learning (pp. 147164). NewYork: Macmillan.

Ferrini-Mundy, J., McCrory, R., \& Senk, S. (2006, April). Knowledge of algebra teaching: Framework, item development, and pilot results. Paper presented at the Research Presession of Annual Meeting of the National Council of Teachers of Mathematics. St. Louis: MO.

Filloy, E., \& Sutherland, R. (1996). Designing curricula for teaching and learning algebra. In A. J. Bishop, K. Clements, C. Keitel, J. Kilpatrick, \& C. Laborde (Eds.), International handbook of mathematics education (Vol. 1, pp. 139-160). Dordrecht, the Netherlands: Springer.

Gallardo, A. (2000). Historical-epistemological analysis in mathematics education: Two works in didactics of algebra. In R. Sutherland, T. Rojano, A. Bell, \& R. Lins (Eds.), Perspective on school algebra (pp. 121-139). Dordrecht, The Netherlands: Kluwer Academic Publishers.

Graeber, A., \& Tirosh, D. (2008). Pedagogical content knowledge: Useful concept or elusive notion. In P. Sullivan, \& T. Wood (Eds.), The international handbook of mathematics teacher education (pp. 117-132). Rotterdam: Sense Publishers. 
Grossman, P. L. (1990). The making of a teacher: Teacher knowledge and teacher education. New York: Teachers College.

Gunnarsson, R., Sönnerhed, W. W., \& Hernell, B. (2016). Does it help to use mathematically superfluous brackets when teaching the rules for the order of operations? Educational Studies in Mathematics, 92(1), 91-105.

Hallagan, J. E. (2004). A teacher's model of students' algebraic thinking about equivalent expressions. In M. J. Hoines, \& A. B. Fuglestad (Eds.), Proceedings of the 28th Conference of the International Group for the Psychology of Mathematics Education (Vol. 3, pp. 1-8). Bergen, Norway: International Group for the Psychology of Mathematics Education.

Hill, H. C., Ball, D. B., \& Schilling, S. G. (2008). Unpacking pedagogical content knowledge: Conceptualizing and measuring teachers' topic-specific knowledge of students. Journal for Research in Mathematics Teacher Education, 39(4), 372-400.

Hill, H. C., Rowan, B., \& Ball, D. L. (2005). Effects of mathematical knowledge for teaching on student achievement. American Educational Research Journal, 42(2), 371406.

Hill, H. C., Sleep, L., Lewis, J. M., \& Ball, D. L. (2007). Assessing teachers' mathematical knowledge: What knowledge matters and what evidence counts? In F. K. Lester (Ed.), Second handbook of research on mathematics teaching and learning (pp. 257-315). Reston, VA: National Council of Teachers of Mathematics.

Hoch, M., \& Dreyfus, T. (2004). Structure sense in high school algebra: The effect of brackets. In M. J. Høines, \& A. B. Fuglestad (Eds.), Proceedings of the 28th Conference of the International Group for the Psychology of Mathematics Education (Vol. 3, pp. 49-56). Bergen: PME.

Huang, R., \& Kulm, G. (2012). Prospective middle-grade mathematics teachers' knowledge of algebra for teaching. The Journal of Mathematical Behavior, 31(4), 417-430.

Kahan, J. A., Cooper, D. A., \& Bethea, K. A. (2003). The role of mathematics teachers' content knowledge in their teaching: A framework for research applied to a study of student teachers. Journal of Mathematics Teacher Education, 6(3), 223-252.

Kaput, J. J. (2000). Teaching and learning a new algebra with understanding. U.S. Department of Education Office of Educational Research and Improvement (OERI) Educational Resources Information Center. (ERIC Document Reproduction Service No. ED441 662).

Kieran, C. (2007). Learning and teaching algebra at the middle school from college levels: Building meaning for symbols and their manipulation. In F. K. Lester (Ed.), Second handbook of research on mathematics teaching and learning (pp.707-762). Charlotte, NC: Information Age.

Kieran, C. (1989). The early learning of algebra: A structural perspective. In S. Wagner, \& C. Kieran (Eds.), Research issues in the learning and teaching of algebra (pp. 33-56), Reston, Virginia: NCTM, and Hillsdale, N.J.: Erlbaum. 
Lepak, J. R., Wernet, J. L., \& Ayieko, R. A. (2018). Capturing and characterizing students' strategic algebraic reasoning through cognitively demanding tasks with focus on representations. The Journal of Mathematical Behavior, 50, 57-73.

Livneh, D., \& Linchevski, L. (2007). Algebrification of arithmetic: Developing algebraic structure sense in the context of arithmetic. In J. W. Woo, H. C., Lew, K. S. Park, \& D. Y. Seo (Eds.), Proceedings of the 31st Conference of the Psychology of Mathematics Education (Vol. 3, pp. 217-225). Seoul, Korea: International Group for the Psychology of Mathematics Education.

Livy, S., \& Downton, A. (2018). Exploring experiences for assisting primary pre-service teachers to extend their knowledge of student strategies and reasoning. The Journal of Mathematical Behavior, 51, 150-160.

Lucariello, J., Tine, M. T., \& Ganley, C. M. (2014). A formative assessment of students' algebraic variable misconceptions. The Journal of Mathematical Behavior, 33, 30-41.

MacGregor, M., \& Stacey, K. (1997). Students' understanding of algebraic notation: 11-15. Educational Studies in Mathematics, 33(1), 1-19.

Malara, N. A., \& Navarra, G. (2009). The analysis of classroom-based processes as a key task in teacher training for the approach to early algebra. In B. Clarke, B. Grevholm, \& R. Millman (Eds.), Tasks in primary mathematics teacher education (pp. 235-262). Berlin: Springer.

Marchini, C., \& Papadopoulos, I. (2011). Are useless brackets useful for teaching? In B. Ubuz (Ed.), Proceedings of the 35th Conference of the International Group for the Psychology of Mathematics Education (Vol. 3, pp. 185-192). Ankara: PME.

Merriam, S. B. (2009). Qualitative research: A guide to design and implementation: Revised and expanded from qualitative research and case study applications in education. San Francisco: Jossey-Bass.

Molina, M., Rodríguez-Domingo, S., Cañadas, M. C., \& Castro, E. (2017). Secondary school students' errors in the translation of algebraic statements. International Journal of Science and Mathematics Education, 15(6), 1137-1156.

Nathan, M. J., \& Koedinger, K. R. (2000). An investigation of teachers' beliefs of students' algebra development. Cognition and Instruction, 18(2), 209-237.

National Council of Teachers of Mathematics [NCTM]. (2000). Principles and standards for school mathematics. Reston, VA: Author.

Novotná, J., \& Hoch, M. (2008). How structure sense for algebraic expressions or equations is related to structure sense for abstract algebra. Mathematics Education Research Journal, 20(2), 93-104.

Ojose, B. (2015). Common misconceptions in mathematics: Strategies to correct them. America: University Press of America.

Prendergast, M., \& O'Donoghue, J. (2014). 'Students enjoyed and talked about the classes in the corridors': Pedagogical framework promoting interest in algebra. International Journal of Mathematical Education in Science and Technology, 45(6), 795-812. 
Rowland, T., Huckstep, P., \& Thwaites, A. (2005). Elementary teachers' mathematics subject knowledge: The knowledge quartet and the case of Naomi. Journal of Mathematics Teacher Education, 8(3), 255-281.

Seng, L. K. (2010). An error analysis of form 2 (grade 7) students in simplifying algebraic expressions: A descriptive study. Electronic Journal of Research in Educational Psychology, 8(1), 139-162.

Shulman, L. S. (1986). Those who understand: Knowledge growth in teaching. Educational Researcher, 15(2), 4-14.

Stephan, M., Pugalee, D., Cline, J., \& Cline, C. (2017). Lesson imagining in math and science: Anticipating student ideas and questions for deeper STEM learning. Alexandria, VA: ASCD.

Stephens, A. C. (2008). What "counts" as algebra in the eyes of preservice elementary teachers? The Journal of Mathematical Behavior, 27(1), 33-47.

Stump, S. (1999). Secondary mathematics teachers' knowledge of slope. Mathematics Education Research Journal, 11(2), 124-144.

Subramaniam, K., \& Banerjee, R. (2004). Teaching arithmetic and algebraic expressions. In M. J. Hoines, \& A. B. Fuglestad (Eds.), Proceedings of the $28^{\text {th }}$ Conference of the International Group for the Psychology of Mathematics Education (Vol. 3, pp. 121128). Bergen, Norway: International Group for the Psychology of Mathematics Education.

Sullivan, P. (2018). Supporting teachers in improving their knowledge of mathematics. The Journal of Mathematical Behavior, 51, 161-166.

Sullivan, P., Askew, M., Cheeseman, J., Clarke, D., Mornane, A., Roche, A., \& Walker, N. (2015). Supporting teachers in structuring mathematics lessons involving challenging tasks. Journal of Mathematics Teacher Education, 18(2), 123-140.

Tchoshanov, M., Quinones, M. C., Shakirova, K. B., Ibragimova, E. N., \& Shakirova, L. R. (2017). Analyzing connections between teacher and student topic-specific knowledge of lower secondary mathematics. The Journal of Mathematical Behavior, 47, 54-69.

Tirosh, D., Even, R., \& Robinson, N. (1998). Simplifying algebraic expressions: Teacher awareness and teaching approaches. Educational Studies in Mathematics, 35, 51-64.

Usiskin, Z. (1988). Conceptions of school algebra and uses of variables. In A. F. Coxford (Ed.), The ideas of algebra, K-12 (pp. 8-19). Reston, VA; National Council of Teachers of Mathematics.

Van Dooren, W., Verschaffel, L., \& Onghena, P. (2002). The impact of preservice teachers' content knowledge on their evaluation of students' strategies for solving arithmetic and algebra word problems. Journal for Research in Mathematics Education, 33(5), 319351.

Weinberg, A., Dresen, J., \& Slater, T. (2016). Students' understanding of algebraic notation: A semiotic systems perspective. The Journal of Mathematical Behavior, 43, 70-88. 
Wilkie, K. J. (2014). Upper primary school teachers' mathematical knowledge for teaching functional thinking in algebra. Journal of Mathematics Teacher Education, 17(5), 397428.

Yin, R. K. (2003). Case study research: Design and methods (3rd ed.). Thousand Oaks, California: Sage Publications. 